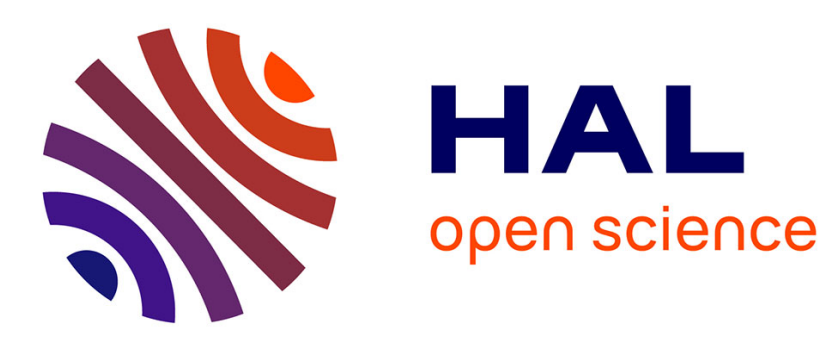

\title{
Local Approach to Strength Mis-Match Effect on Cleavage Fracture of Notched Material
}

\author{
M. Ohata, F. Minami, M. Toyoda
}

\section{To cite this version:}

M. Ohata, F. Minami, M. Toyoda. Local Approach to Strength Mis-Match Effect on Cleavage Fracture of Notched Material. Journal de Physique IV Proceedings, 1996, 06 (C6), pp.C6-269-C6-278. 10.1051/jp4:1996626 . jpa-00254454

\section{HAL Id: jpa-00254454 https://hal.science/jpa-00254454}

Submitted on 1 Jan 1996

HAL is a multi-disciplinary open access archive for the deposit and dissemination of scientific research documents, whether they are published or not. The documents may come from teaching and research institutions in France or abroad, or from public or private research centers.
L'archive ouverte pluridisciplinaire HAL, est destinée au dépôt et à la diffusion de documents scientifiques de niveau recherche, publiés ou non, émanant des établissements d'enseignement et de recherche français ou étrangers, des laboratoires publics ou privés. 


\title{
Local Approach to Strength Mis-Match Effect on Cleavage Fracture of Notched Material
}

\author{
M. Ohata, F. Minami and M. Toyoda \\ Department of Welding and Production Engineering, Osaka University, 2-1 Yamada-Oka, Suita, Osaka, \\ Japan
}

\begin{abstract}
This paper discusses the strength mis-match effect on cleavage fracture of notched materials based on the local approach. The aim of the study is to verify the independence of the critical Weibull stress at fracture on the strength mis-match condition. Diffusion bonded joints were made with two materials $\mathrm{S}$ and $\mathrm{H}$ different in strength level. Two types of 3-point bend specimen were extracted. One had a notch in the lower strength material $\mathrm{S}$ near the bonded interface, and another in the higher strength material $\mathrm{H}$. Homogeneous specimens were also made for each material. The critical CTOD value at cleavage fracture for the overmatched specimen with a notch in the material $\mathrm{S}$ was smaller than that of the homogeneous specimen of the material S. By contrast, the undermatched specimen with a notch in the material $H$ showed apparently larger critical CTOD value than the homogeneous specimen of the material $\mathrm{H}$. The strength mis-match effect on the CTOD results was explained in terms of the constraint effect on the near-tip stress field. Namely, the near-tip stress is elevated by strength overmatching and relaxed by strength undermatching. The Weibull stresses for the homogeneous and mis-matched specimens were evaluated in the light of the near-tip stress fields. The critical Weibull stress at fracture did not depend on the strength mis-match condition near the notch. By using the critical Weibull stress obtained for the homogeneous specimen, the strength mis-match effect on the CTOD results can be predicted. Close agreement was observed between the critical CTOD value predicted and that obtained by the experiment.
\end{abstract}

\section{INTRODUCTION}

Strength mis-matching between the base and weld metals in welded joints imposes a complex problem in fracture toughness evaluation of welds. Locating a notch in the HAZ (heat affected zone) along the fusion line of mis-matched welds brings about asymmetrical crack opening [1-3]. This implies that the conventional fracture mechanics parameter such as the total CTOD (crack tip opening displacement) is not always applicable to mis-matched welds. Strength mis-matching exerts an influence also on the fracture resistance of welds. There are many experimental observations that the critical CTOD value of HAZ notched specimens decreases with increasing the strength level of the weld metal $[4,5]$. This is due to the constraint effect by strength mis-matching on the stress field in the HAZ. For instance, the strength overmatch of the weld metal elevates a local stress in the HAZ [6], which promotes fracture initiation in the $\mathrm{HAZ}$ at a lower CTOD level than matched welds.

In this study, the strength mis-match effect on fracture properties of notched specimens was discussed on the basis of the local approach $[7,8]$. The dependence of cleavage resistance and the fracture initiation location on the mechanical heterogeneity in the vicinity of the notch tip was focused. Three dimensional FE-analysis was conducted to address the strength mis-match effect on the stress distribution around the notch tip. The major purpose of this study is to demonstrate the independence of the critical Weibull stress at fracture on the strength mis-match condition near the notch.

\section{STRENGTH MIS-MATCH EFFECT ON CTOD RESULTS OF NOTCHED MATERIAL}

Diffusion bonding of SM490 steel and HT780 steel was conducted to present a large degree of strength mis-matching. Table 1 gives the chemical composition of these steels. The plate thickness of each steel 
Table 1 Chemical composition and mechanical properties of materials $\mathrm{S}$ and $\mathrm{H}$ used.

\begin{tabular}{|c|c|c|c|c|c|c|c|c|c|c|c|c|c|}
\hline & \multicolumn{11}{|c|}{ Chemical composition (mass\%) } & \multirow{2}{*}{$\begin{array}{l}\text { Ceq } \\
(\%)\end{array}$} & \multirow{2}{*}{$\begin{array}{l}\text { Pcm } \\
(\%)\end{array}$} \\
\hline & C & $\mathrm{Si}$ & Mn & $\mathbf{P}$ & $S$ & $\mathrm{Cu}$ & $\mathrm{Ni}$ & $\mathrm{Cr}$ & Mo & V & B & & \\
\hline $\begin{array}{c}\text { SM490 } \\
\text { (Material S) }\end{array}$ & 0.14 & 0.36 & 1.41 & 0.010 & 0.003 & 0.28 & 0.19 & - & - & - & - & 0.41 & 0.24 \\
\hline \multirow[t]{3}{*}{$\begin{array}{c}\text { HT780 } \\
\text { (Material H) }\end{array}$} & 0.10 & 0.23 & 0.97 & 0.007 & 0.001 & - & 1.21 & 0.46 & 0.45 & 0.04 & 0.001 & 0.51 & 0.26 \\
\hline & & & \multicolumn{11}{|c|}{$\begin{array}{l}\mathrm{Ceq}=\mathrm{C}+\mathrm{Mn} / 6+(\mathrm{Cr}+\mathrm{Mo}+\mathrm{V}) / 5+(\mathrm{Ni}+\mathrm{Cu}) / 15 \\
\mathrm{Pcm}=\mathrm{C}+\mathrm{Si} / 30+(\mathrm{Mn}+\mathrm{Cu}+\mathrm{Cr}) / 20+\mathrm{Ni} / 60+\mathrm{Mo} / 15+\mathrm{V} / 10+5 \mathrm{~B}\end{array}$} \\
\hline & & & \multicolumn{3}{|c|}{$\sigma_{Y}(\mathrm{MPa})$} & \multicolumn{2}{|c|}{$\sigma_{\mathrm{T}}(\mathrm{MPa})$} & & \multicolumn{2}{|c|}{ YR (\%) } & & \multicolumn{2}{|c|}{$\varepsilon_{T}(\%)$} \\
\hline \multicolumn{3}{|c|}{$\begin{array}{c}\text { Material S } \\
\text { (After heat treatment) }\end{array}$} & \multicolumn{3}{|c|}{283} & \multicolumn{2}{|c|}{472} & & \multicolumn{2}{|c|}{60} & & \multicolumn{2}{|l|}{15.9} \\
\hline \multicolumn{3}{|c|}{$\begin{array}{c}\text { Material } \mathrm{H} \\
\text { (After heat treatment) }\end{array}$} & \multicolumn{2}{|r|}{533} & & \multicolumn{2}{|c|}{717} & & \multicolumn{2}{|c|}{74} & & \multicolumn{2}{|l|}{6.10} \\
\hline
\end{tabular}

$\sigma_{\mathrm{Y}}:$ Yield stress $(0.2 \%$ proof stress $), \sigma_{\mathrm{T}}:$ Tensile strength

YR : Yield to tensile ratio $\left(=\sigma_{\mathrm{Y}} / \sigma_{\mathrm{T}}\right), \varepsilon_{\mathrm{T}}$ : Uniform elongation

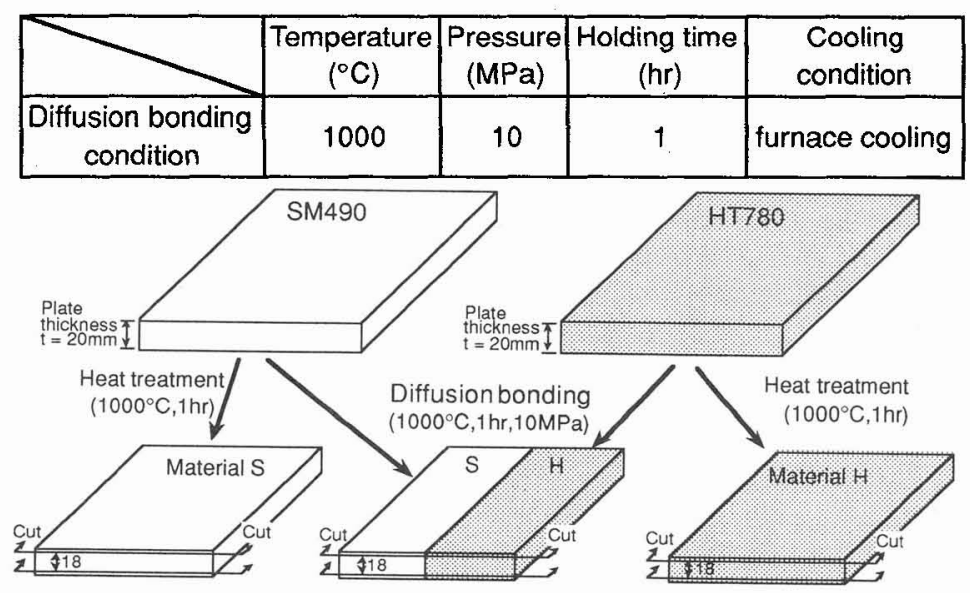

Figure 1 Diffusion bonding and heat treatment of SM490 and HT780 steel plates.

was $20 \mathrm{~mm}$. Figure 1 shows the procedure and condition for diffusion bonding. The SM490 and HT780 steel plates also followed the same heat treatment as used in the diffusion bonding. The surface of the diffusion bonded joints were cut off $1.0 \mathrm{~mm}$ to get the useful bonded interface as shown in Fig. 1 . Mechanical properties of these materials $S$ and $H$ are given in Table 1. In this paper, the SM490 steel and HT780 steel after heat treatment were termed the material $S$ and material $H$, respectively. From the diffusion bonded joints and heat treated plates, 3-point bend specimens were extracted as shown in Fig. 2. In Series I, homogeneous specimens of material S and diffusion bonded specimens with a notch on the material S side near the bonded interface were prepared. The aim of Series I test is to investigate the strength overmatch effect on the fracture property of notched specimens. In this paper the diffusion bonded specimens with a notch in the material $S$ are termed overmatched specimens. On the other hand, Series II pays attention to the strength undermatch effect. Homogeneous specimens of material $\mathrm{H}$ and diffusion bonded specimens with a notch on the material $\mathrm{H}$ side near the interface (undermatched specimens) were used. The microstructures near the bonded interface and apart from the interface were much the same for each material, as shown in Fig.3. Vickers hardness near the interface was also almost the same as that of the homogeneous plate for each material, as presented in Fig. 4. The notch of the overmatched and undermatched specimens was located at a target distance $1.0 \mathrm{~mm}$ from the bonded interface. The actual distance between the notch tip and the interface was in the range 0.8 to $1.25 \mathrm{~mm}$. It is expected that the 


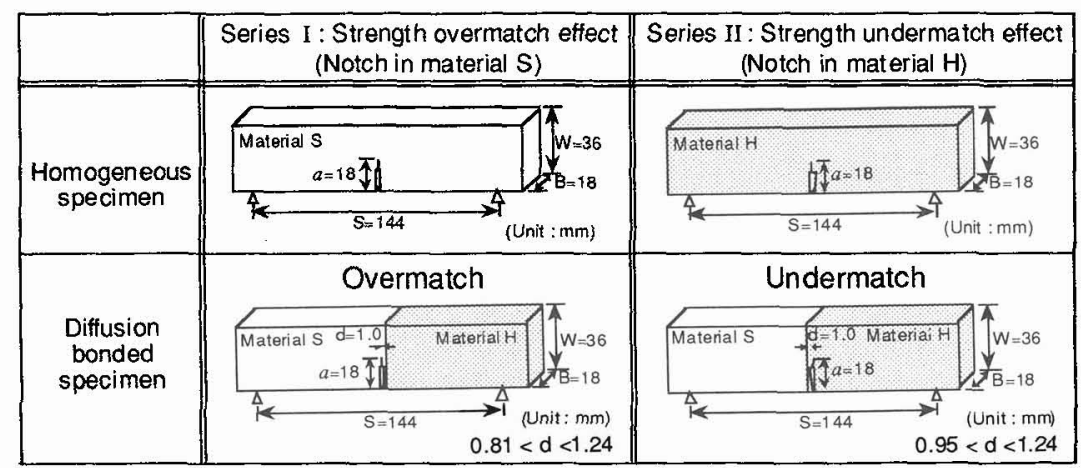

Figure 2 Configuration of 3-point bend specimens.

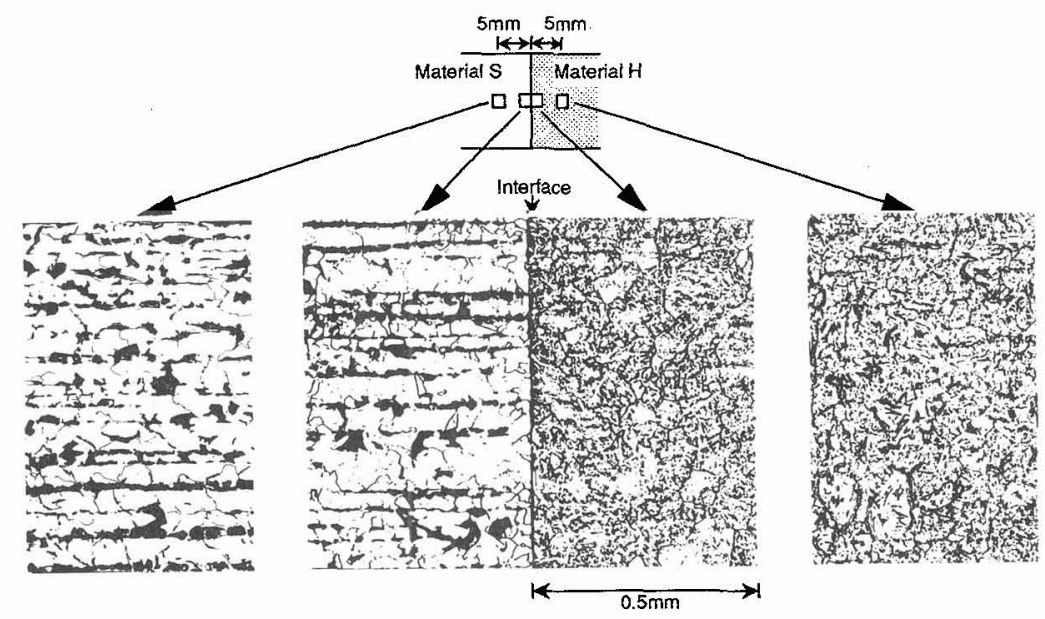

Figure 3 Microstructures of diffusion bonded specimen and homogeneous specimens.

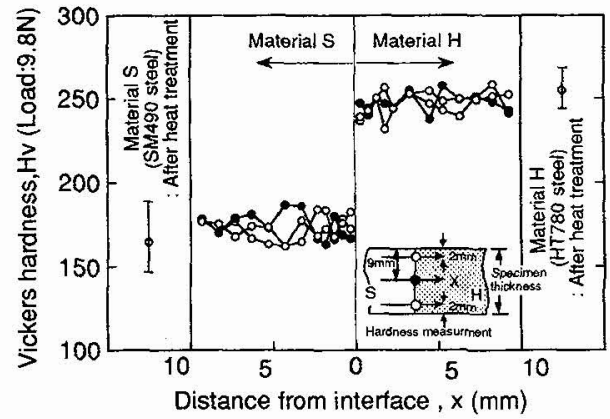

Figure 4 Hardness distribution for diffusion bonded specimens.
Table 2 Mechanical properties of materials $\mathrm{S}$ and $\mathrm{H}$ at test temperature.

\begin{tabular}{|c|c|c|c|c|c|c|c|}
\hline & \multirow{2}{*}{$\begin{array}{c}\sigma_{Y} \\
(\mathrm{MPa})\end{array}$} & \multirow{2}{*}{$\begin{array}{c}\sigma_{\mathrm{T}} \\
(\mathrm{MPa})\end{array}$} & \multirow{2}{*}{$\begin{array}{l}\text { YR } \\
(\%)\end{array}$} & \multirow{2}{*}{$\begin{array}{c}\varepsilon_{T} \\
(\%)\end{array}$} & \multicolumn{2}{|c|}{ Sr } \\
\hline & & & & & & $\sigma_{Y}{ }^{H} / \sigma_{Y} s$ & $\sigma_{Y} s / \sigma_{Y} H$ \\
\hline \multirow{2}{*}{$\begin{array}{l}\text { Series I } \\
\left(-20^{\circ} \mathrm{C}\right)\end{array}$} & Material S & 312 & 520 & 60 & 16.9 & \multirow{2}{*}{1.77} & \\
\hline & Material $\mathrm{H}$ & 551 & 745 & 74 & 6.4 & & \\
\hline \multirow{2}{*}{$\begin{array}{c}\text { Series II } \\
\left(50^{\circ} \mathrm{C}\right)\end{array}$} & Material S & 275 & 455 & 60 & 16.0 & & \multirow{2}{*}{0.51} \\
\hline & Material H & 534 & 697 & 77 & 5.9 & & \\
\hline
\end{tabular}

$\sigma_{Y}:$ Yield stress $\left(0.2 \%\right.$ proof stress) , $\sigma_{T}$ : Tensile strength YR : Yield to tensile ratio $\left(=\sigma_{Y} / \sigma_{\mathrm{T}}\right), \varepsilon_{\mathrm{T}}$ : Uniform elongatior $\sigma_{Y}{ }^{H}, \sigma_{Y}{ }^{S}: \sigma_{Y}$ of materials $H$ and $S$

influence of residual stress on fracture resistance of 3-point bend specimen is marginal, because the residual stress component perpendicular to the notch plane is very small. The geometry of all specimens was $B=18 \mathrm{~mm}$ (specimen thickness) $\times W=36 \mathrm{~mm}$ (specimen width), and the notch length $a$ including fatigue precrack was $18 \mathrm{~mm}(a / W=0.5)$.

3-point bend (3PB) tests of Series I and Series II were conducted at $-20^{\circ} \mathrm{C}$ and at $50^{\circ} \mathrm{C}$, respectively, 
corresponding to a lower temperature in ductile-brittle transition range for each materials $\mathrm{S}$ and $\mathrm{H}$. Table 2 gives the mechanical properties of the materials $\mathrm{S}$ and $\mathrm{H}$ at the test temperature obtained by the round-bar tension test. Yield strength mis-match ratio $\mathrm{Sr}=\sigma_{Y}{ }_{\mathrm{H}} / \sigma_{Y}{ }_{\mathrm{Y}}$ for the overmatched specimen (Series I) was 1.77 and that $\left(=\sigma_{Y}{ }^{\mathrm{S}} / \sigma_{\mathrm{Y}}{ }^{\mathrm{H}}\right)$ for the undermatched specimen (Series II) 0.51 , where $\sigma_{\mathrm{Y}}{ }^{\mathrm{S}}$ and $\sigma_{\mathrm{Y}}{ }^{\mathrm{H}}$ are yield stress $(0.2 \%$ proof stress) of the materials $\mathrm{S}$ and $\mathrm{H}$ at the test temperature, respectively. In the $3 \mathrm{~PB}$ test, the load $P$ - crack mouth opening displacement $V g$ relation was recorded. The critical CTOD for all specimens were calculated according to the British standard BS7448 [9]. The fracture initiation point was investigated by SEM (Scanning Electron Microscope) and the distance from fatigue crack tip to fracture initiation point was measured for all specimens.

Figure 5 presents the cumulative distribution of the critical CTOD value at brittle fracture initiation. Almost all specimens fractured in a brittle manner with stable crack growth less than $0.2 \mathrm{~mm}\left(\delta_{c}\right.$ mode). The fracture initiation point was located near the crack tip. In undermatched specimens, however, 4 specimens (denoted by had fracture initiation point in the adjacent material $S$ apart from the crack tip after large extension of ductile crack toward the lower strength material S. It can be seen that the distribution of the critical CTOD value is affected by the strength mis-matching. The overmatched specimen provides lower critical CTOD value on the average than the homogeneous specimen (Series I). On the other hand, the undermatched specimen gives higher critical CTOD value than the homogeneous specimen (Series II).

Figure 6 exhibits the location of the fracture initiation point for the homogeneous and heterogeneous specimens. The distance $x$ from the fatigue crack tip to the fracture initiation point was normalized by the

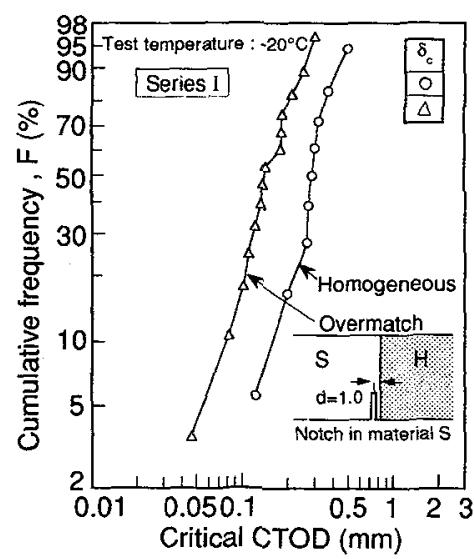

(a) Strength overmatch effect (Series I)

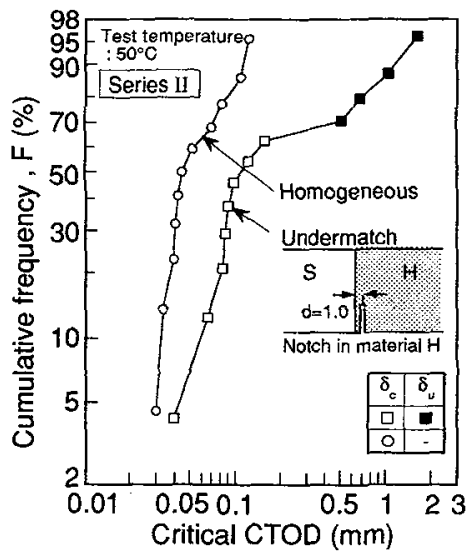

(b) Strength undermatch effect (Series II)

Figure 5 Influence of strength mis-matching on the distribution of critical CTOD value.

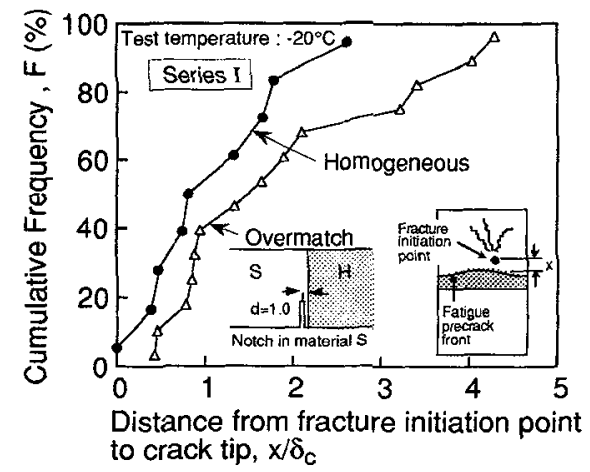

(a) Strength overmatch effect (Series I)

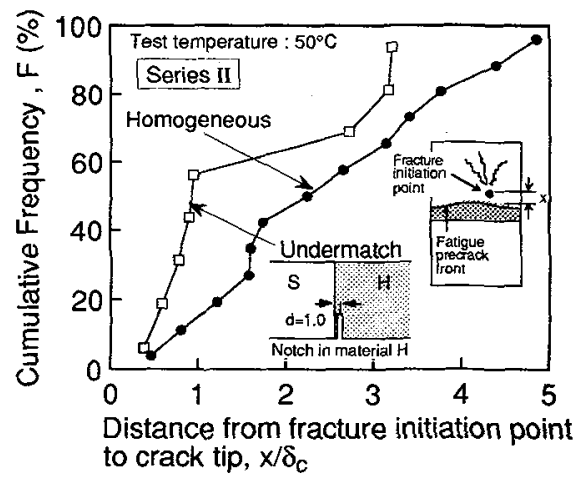

(b) Strength undermatch effect (Series II)

Figure 6 Location of the fracture initiation point in homogeneous and mis-matched specimens. 
critical CTOD $\delta_{\mathrm{c}}$. The overmatched specimen had fracture initiation point at a larger distance from fatigue crack tip than the homogeneous specimen. By contrast, in the undermatched specimen, the fracture initiation point was close to the crack tip.

\section{STRENGTH MIS-MATCH EFFECT ON THE STRESS FIELD NEAR THE CRACK TIP}

The influence of strength mis-matching on the critical CTOD value and the location of the fracture initiation point will be related to the stress field in the vicinity of the crack tip. Three dimensional FEanalysis to address the strength mis-match effect on the near-crack tip stress field was performed.

Figure 7 shows the model of 3-point bend specimens used in the FE-analysis. Because of symmetry in the thickness direction, half of the specimen was modeled. The FE-analysis was conducted by using the non-linear FE-code, JNIKE-3D. 8-node isoparametric elements with 8-Gaussian points were employed. The minimum size of the crack tip element was 0.06 (direction perpendicular to the crack plane) $\times 0.06$ (specimen width direction) $\times 0.5 \mathrm{~mm}$ (specimen thickness direction). The mesh division near the crack tip was common to all specimen geometries. Figure 8 gives the equivalent stress - equivalent strain curves of the materials at the test temperature used in the FE-analysis. These stress-strain curves were obtained by the round-bar tension test.

The load $P$ - crack mouth opening displacement $V g$ relation obtained by the FE-analysis agreed well

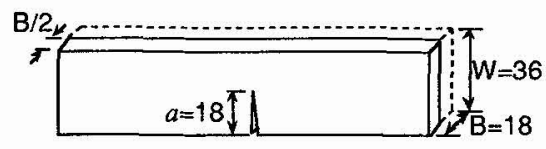

(a) Homogeneous specimen

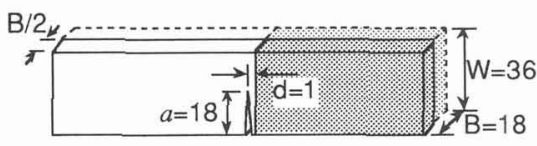

(b) Overmatched and undermatched specimen

Figure 7 FE-models used.

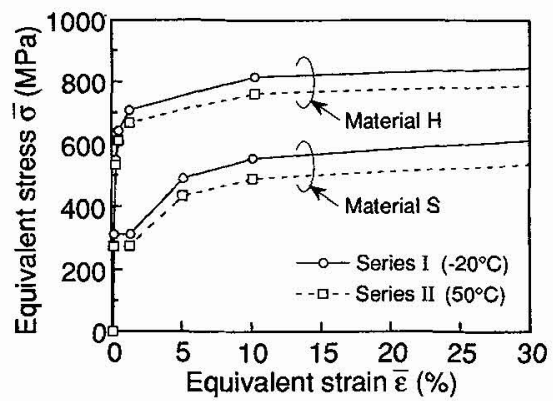

Figure 8 Equivalent stress - equivalent strain curves of materials $\mathrm{S}$ and $\mathrm{H}$ at test temperature used for FE-analysis.

with experimental results. The CTOD in the FE-analysis was calculated according to the same procedure as used in the experiment.

Figure 9 exhibits the distribution of the crack opening stress $\sigma_{y y}$ ahead of the crack tip at the midthickness at a certain CTOD level $(\delta=0.1 \mathrm{~mm}$ in Series I and $\delta=0.05 \mathrm{~mm}$ in Series II). These CTOD levels are in the range of the critical CTOD value for each specimen given in Fig. 5. The overmatched specimen presents a higher opening stress near the crack tip than the homogeneous specimen (Series I). On the other hand, the undermatched specimen gives apparently lower stresses than the homogeneous specimen (Series II). Figure 10 compares the peak opening stress $\left(\sigma_{y y}\right)_{\max }$ between the mis-matched specimen and the homogeneous specimen. The peak stress $\left(\sigma_{\mathrm{yy}}\right)_{\max }$ is elevated by strength overmatching and relaxed by strength undermatching. The relaxation of $\left(\sigma_{y y}^{y y}\right)_{\max }$ for the undermatched specimen is more significant.

Figure 11 exhibits a highly stressed region around the crack tip for the homogeneous and mis-matched specimens. Contours of the maximum principal stress $\sigma_{1}=3.5 \sigma_{Y}{ }^{\mathrm{s}}$ and $4 \sigma_{\mathrm{Y}}{ }^{\mathrm{s}}$ are drawn at the CTOD level $\delta=0.1 \mathrm{~mm}$ for Series I, and those of $\sigma_{1}=3 \sigma_{Y}{ }^{\mathrm{H}}$ at $\delta=0.05 \mathrm{~mm}$ for Series II. The overmatched specimen provides a larger extent of highly stressed region than the homogeneous specimen (Series I). By contrast, in the undermatched specimen, the highly stressed region is apparently small compared to that of the homogeneous specimen (Series II). Similar behavior was observed at other CTOD levels.

These analytical results indicate that the strength mis-match effect on the CTOD test results is attributed to the constraint effect on the near-tip stress field. The strength overmatching activates the stress field ahead of the crack tip, which led to the decrease in the critical CTOD value. On the other hand, the strength undermatching relaxes the near-crack tip stress field, so that the critical CTOD value is increased apparently. The change in fracture initiation location with strength mis-matching also corresponds to the respective near-tip stress field.

The analytical results in Figs. 9 to 10 suggest that the conventional CTOD, total CTOD, does not 


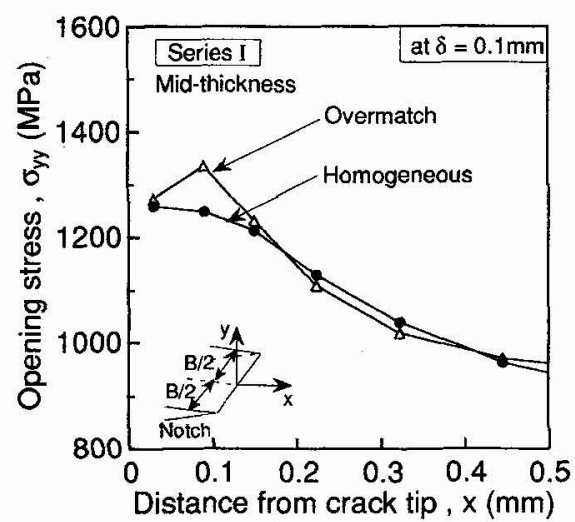

(a) Strength overmatch effect (Series I)

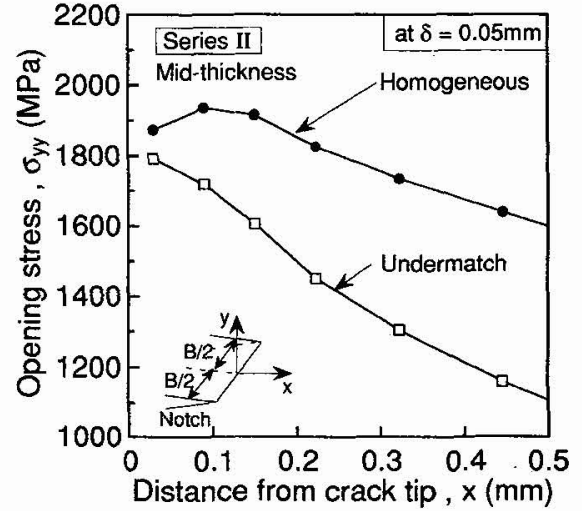

(b) Strength undermatch effect (Series II)

Figure 9 Distributions of crack opening stress $\sigma_{y y}$ ahead of the crack tip for homogeneous and mis-matched specimens.

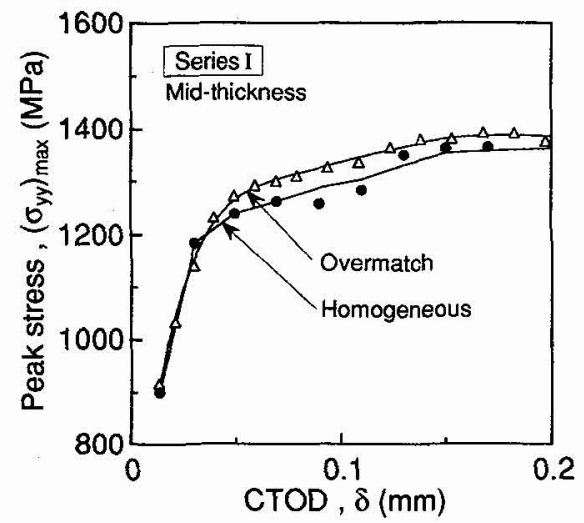

(a) Strength overmatch effect (Series I)

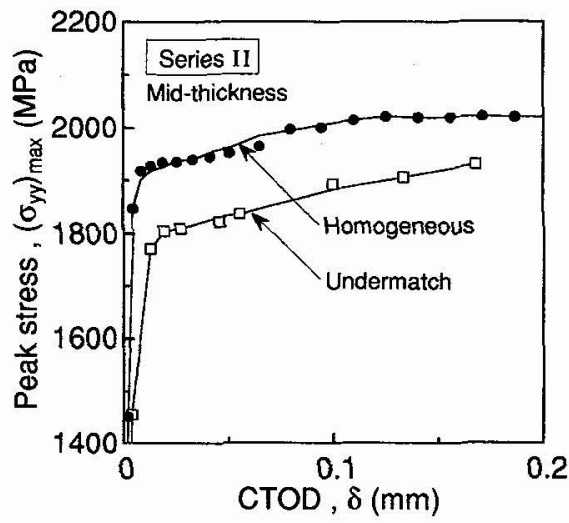

(b) Strength undermatch effect (Series II)

Figure 10 Influence of strength mis-matching on peak stress $\left(\sigma_{y y}\right)_{\max }$ near-crack tip.

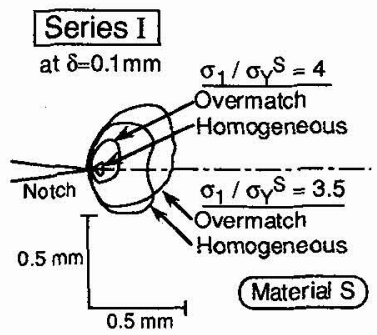

(a) Strength overmatch effect (Series I)

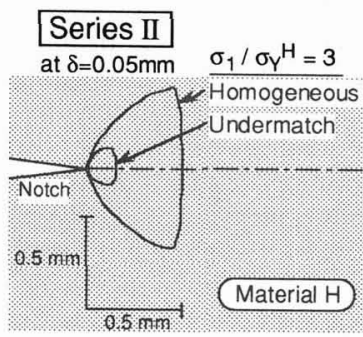

(b) Strength undermatch effect (Series II)

Figure 11 Contours of the maximum principal stress around the crack tip at mid-thickness.

control the near-tip stress field for mis-matched specimens. For specimens with a notch along the interface of dissimilar materials, the local CTOD $\delta_{\text {Local }}$ considering asymmetrical crack opening was proposed [10]. Figure 12 provides the distribution of the crack opening stress $\sigma_{y y}$ ahead of the crack tip as a function of $\mathrm{x} /$ $\delta_{\text {Local }}$ for 3PB specimens in Series I and II. The local CTOD $\delta_{\text {Local }}^{\text {yy }}$ was evaluated as $\delta_{\text {Local }}=2 \delta^{*}$, where $\delta^{*}$ 


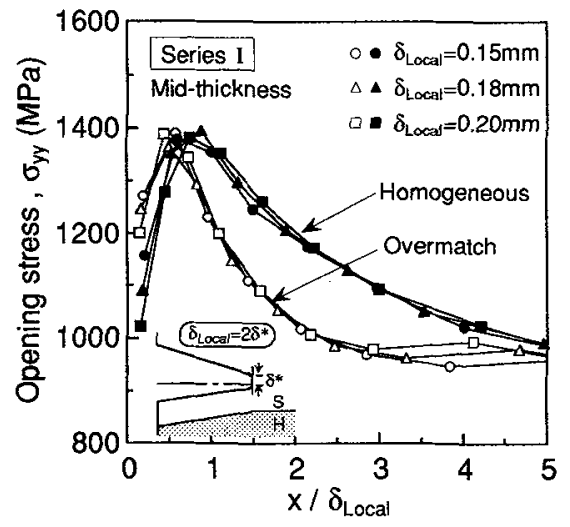

(a) Strength overmatch effect (Series I)

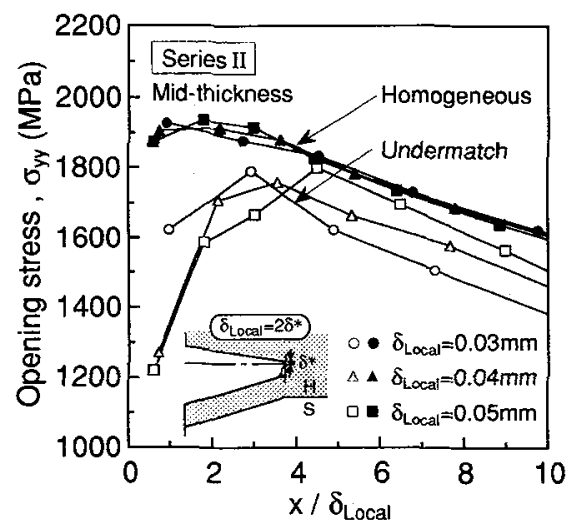

(b) Strength undermatch effect (Series II)

Figure 12 Opening stress distributions in the vicinity of the crack tip as a function of the parameter $x / \delta_{\text {Local }}$.

is the local crack tip opening in the opposite direction to the bonded interface. The $\delta^{*}$ was calculated by using the tangential method [11]. In the case of the homogeneous specimen, the local CTOD is equal to the total CTOD. Figure 12 indicates that even the local CTOD does not always control the near-tip stress field of for mis-matched specimens.

\section{APPLICATION OF THE LOCAL APPROACH TO FRACTURE RESISTANCE EVALUATION OF MIS-MATCHED SPECIMENS}

\subsection{Local Approach}

In this study, the Weibull stress, proposed in the local approach [7,8], was applied to evaluate the fracture driving force for notched materials with strength mis-matching. The Weibull stress $\sigma_{w}$ is given by the integration of the near-tip stress over the fracture process zone $V_{f}$ in the form

$$
\sigma_{\mathrm{W}}=\left[\frac{1}{\mathrm{~V}_{0}} \int_{\mathrm{V}_{\mathrm{f}}}\left[\sigma_{\mathrm{eff}}\right]^{m} \mathrm{dV}_{\mathrm{f}}\right]^{1 / m}
$$

where $m$ is the Weibull shape parameter of the material and $V_{0}$ is a reference volume of a fracture unit defined in the local approach. With respect to the near-tip stress, the effective stress $\sigma_{\text {eff }}$ [12] was used, considering multiaxial stress state near the notch tip and random spacial distribution of microcracks in the fracture process zone

$$
\sigma_{\mathrm{eff}}=\left[\frac{1}{2 \pi} \int_{0}^{\pi} \int_{0}^{\pi}\left[\sigma_{\mathrm{n}}^{2}+\frac{4}{(2-v)^{2}} \tau^{2}\right]^{m / 2} \sin \theta \mathrm{d} \theta \mathrm{d} \varphi\right]^{1 / m}
$$

where $\sigma_{n}$ and $\tau$ are the normal stress and the in-plane maximum shear stress for the microcrack, respectively, and the angles $\theta$ and $\varphi$ define the orientation of the microcrack relative to the principal stress axis.

According to the local approach, the critical Weibull stress $\left(\sigma_{\mathrm{w}}\right)_{\mathrm{cr}}$ at brittle fracture initiation obeys the Weibull distribution with the two parameters $m$ and $\sigma_{u}$ in the form 


$$
\mathrm{F}\left[\left(\sigma_{\mathrm{W}}\right)_{\mathrm{cr}}\right]=1-\exp \left[-\left(\frac{\left(\sigma_{\mathrm{W}}\right)_{\mathrm{cr}}}{\sigma_{\mathrm{u}}}\right)^{m}\right]
$$

In eq. (3) $m$ and $\sigma_{u}$-values are material constants independent of the specimen geometry.

\subsection{Cleavage Resistance Evaluated by Weibull Stress}

First, the fracture resistance of the homogeneous and mis-matched specimens was evaluated by the Weibull stress. The fracture process zone $V_{f}$ for the diffusion bonded specimen was taken from the activated region of the material on the notch side. With respect to the reference volume $V_{0}$, a unit volume $1 \mathrm{~mm}^{3}$ was adopted for convenience, because the selection of volume $\mathrm{V}_{0}$ does not affect the $m$-value. In this paper, the Weibull parameters $m$ and $\sigma_{\mathrm{u}}$ were determined by using the iterative procedure [14] with the maximum likelihood method. The integration of the effective stress $\sigma_{\text {eff }}$ was performed by the Gaussian quadrature [15] based on the 3D FE-results.

Table 3 summarizes the maximum likelihood estimation of the Weibull parameters $m$ and $\sigma_{u}$ and their $90 \%$ confidence limits [16] for the homogeneous and mis-matched specimens. With respect to the undermatched specimen, in some of which the fracture initiation point was observed in the adjacent material (Material S) after significant amount of crack growth, the least square method was applied. The homogeneous specimen and the mis-matched specimen have almost the same Weibull parameters in both Series I and II. The strength mis-match independence of the critical Weibull stress has been also shown by anthor's recent results [17], where three-point bend specimens with a notch between parallel Laser welds (hard zones) were tested.

Table 3 Weibull parameters and $90 \%$ confidence limits.

\begin{tabular}{|c|c||c|c|c|c|}
\hline \multicolumn{2}{|c||}{} & $\begin{array}{r}\text { Maximum likelihood } \\
\text { estimation }\end{array}$ & \multicolumn{2}{c|}{$90 \%$ confidence limits } \\
\cline { 2 - 6 } & $\mathrm{m}$ & $\sigma_{\mathrm{u}}(\mathrm{MPa})$ & $\mathrm{m}$ & $\sigma_{\mathrm{u}}(\mathrm{MPa})$ \\
\hline \hline $\begin{array}{c}\text { Series I } \\
\left(-20^{\circ} \mathrm{C}\right)\end{array}$ & Homogeneous & 40 & 1246 & $(24,54)$ & $(1223,1269)$ \\
\cline { 2 - 7 } & Overmatch & 31 & 1197 & $(19,41)$ & $(1177,1218)$ \\
\hline $\begin{array}{c}\text { Series II } \\
\left(50^{\circ} \mathrm{C}\right)\end{array}$ & Homogeneous & 43 & 1773 & $(25,58)$ & $(1748,1799)$ \\
\cline { 2 - 7 } & Undermatch & $43 *$ & $1739 *$ & & \\
\hline
\end{tabular}

\subsection{Prediction of Strength Mis-Match Effect on Critical CTOD by the Local Approach}

Based on the local approach, the strength mis-match effect on the critical CTOD value was predicted. Figure 13 shows the procedure for prediction. According to the local approach, the critical Weibull stress distribution is given as a material property independent of the strength mis-matching. Then, the necessary procedure for prediction is to calculate the Weibull stress - CTOD relationship for the mis-matched specimen by using the m-parameter obtained from the homogeneous specimen. Connecting the CTOD value of the target specimen with the corresponding failure probability by way of the Weibull stress $\sigma_{\mathrm{w}}$, the cumulative distribution of the critical CTOD value for the target specimen can be derived. Figure 14 shows the predicted distribution of the critical CTOD for the overmatched and undermatched specimens. The predicted results show a good agreement with the experimental results. 


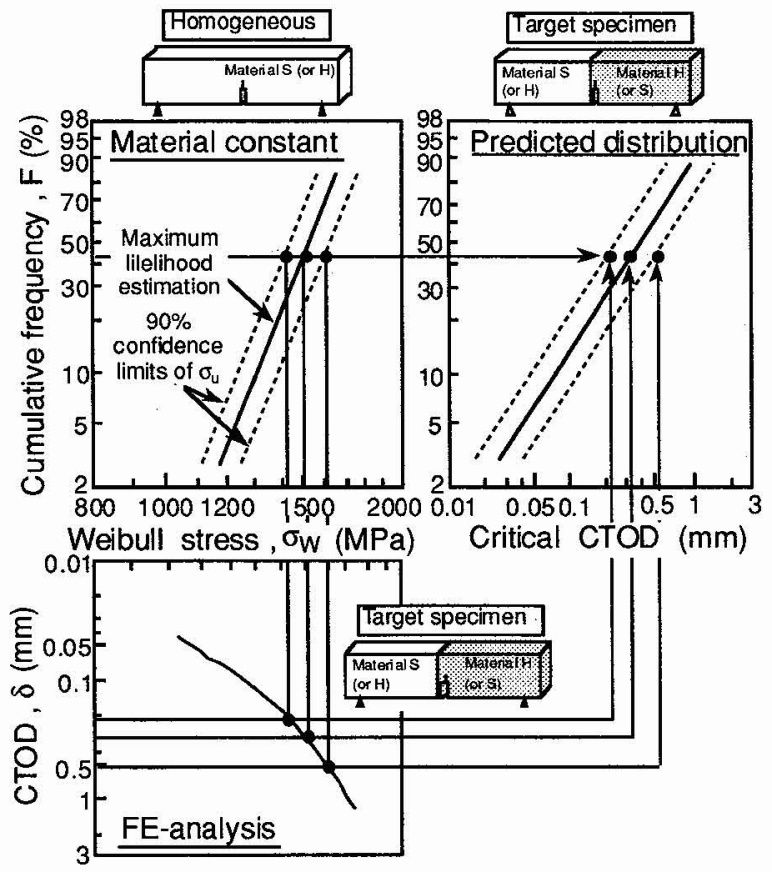

Figure 13 Procedure to predict the critical CTOD value for mis-matched specimens from test results of homogeneous specimens.

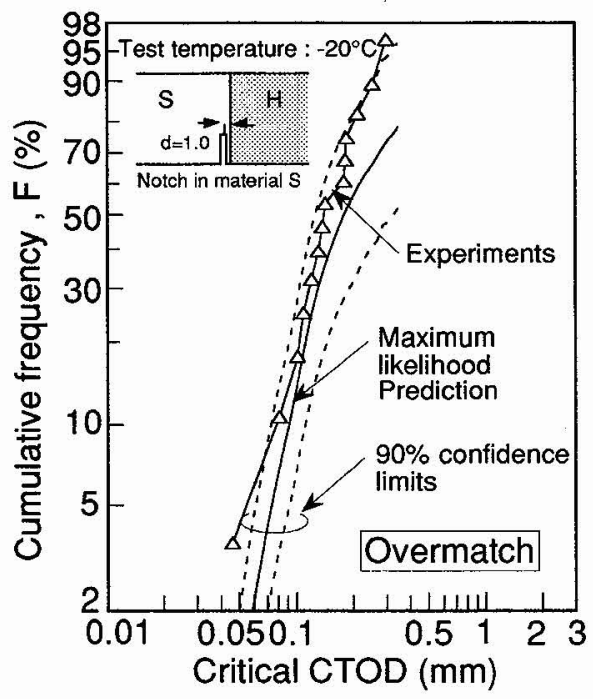

(a) Prediction of strength overmatch effect

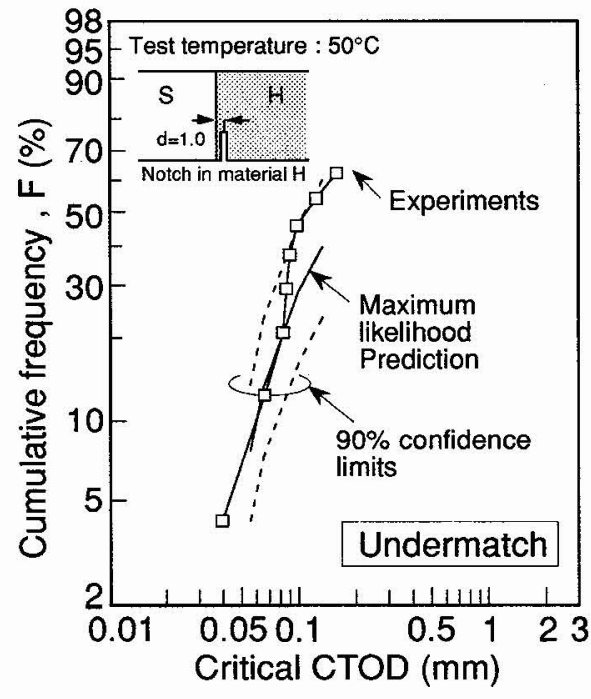

(b) Prediction of strength undermatch effect

Figure 14 Distribution of critical CTOD values for mis-matched specimens predicted by the local approach. 


\section{CONCLUSIONS}

In this study, the local approach was applied to evaluate the fracture resistance of notched material with strength mis-matching. The influence of strength mis-matching on the critical CTOD value at fracture can be explained in terms of the constraint effect. The strength overmatching elevated the stress field ahead of the crack tip, which led to the decrease in the critical CTOD value. By contrast, a relaxation of the nearcrack tip stress field was observed in the undermatched specimen, which was the reason for the increase in the critical CTOD value. With these properties in mind, the Weibull stress $\sigma_{\mathrm{W}}$ was employed for the evaluation of fracture resistance of mis-matched specimens. It was demonstrated that the critical Weibull stress $\left(\sigma_{\mathrm{W}}\right)_{\mathrm{cr}}$ at brittle fracture initiation was independent of strength mis-matching near the notch tip.

\section{References}

[1] Satoh K. and Toyoda M., "Fracture Toughness Evaluation of Welds with Mechanical Heterogeneity," Transaction of the Japan Welding Society, 13 No. 1 (1982).

[2] Toyoda M. and Satoh K., "Fracture Toughness of Welds : The Incidence of Mechanical Heterogeneity in the Correlation of Toughness Parameters," Welding in the World, 22 (1984) pp.7686.

[3] Thaulow C., Larsen A., Ranestad O. and Hauge M., "Effect of Local Strength Mismatch on CTOD Toughness in the HAZ of Steel Weldments," IIW Doc. X-F-007-94, Weld Mis-Match Effect, Paris (1994).

[4] Koçak M., Schwalbe K. -H., Chen L. and Gnirss G., "Effect of Notch Position and Weld Metal Matching on CTOD of HAZ," Int. Conf. Weld Failures, London, England (1988).

[5] Minami F., Nakano Y., Suzuki S., Shiwaku T., Moriya Y., Hagiwara Y. and Toyoda M., "Fracture Toughness Evaluation of Multipass Weld HAZ with Focus on Mechanical Mis-Matching Effect," Quarterly Journal of Japan Welding Society, 12 (1994) No.4 pp.568-574 (in Japanese).

[6] Ruggieri C., Minami F. and Toyoda M., "Effects of Strength Mismatch on Crack Tip Stress Fields of HAZ-Notched Joints Subjected to Bending and Tension," Jl. Naval. Archit. Japan, 174 (1993) pp.543-549.

[7] Beremin F. M., "A Local Criterion for Cleavage Fracture of a Nuclear Pressure Vessel Steel," Metallurgical Trans. A, 14A (1983) pp.2277-2287.

[8] Mudry F., "A Local Approach to Cleavage Fracture," Nuclear Engineering Design, 105 (1987) 6576.

[9] BS7448, Part 1 Fracture Mechanics Toughness Tests, Method for Determination of $\mathrm{K}_{\mathrm{IC}}$, Critical CTOD and Critical J Values of Metallic Materials, British Standard Institution (1991).

[10] Satoh K., Toyoda M., Minami F., Arimochi K., Nakanishi M. and Satoh S., "A Proposal of Generalized COD Criterion and Its Application to Welds," Quarterly Journal of Japan Welding Society, 2 (1984) pp.447-454.

[11] Harrison J. D., "The State-of-the-Art in Crack Tip Opening Displacement (CTOD) Testing and Analysis," Part 1 - Background and Testing Methods, Metal Construction, 12 (1980) pp.415-422.

[12] Minami F., Brückner-Foit A. and Trolldenier B., "Numerical Procedure for Determining Weibull Parameters Based on the Local Approach," Preprints of 8th Biennial European Conference on Fracture - ECF8, Torino, 1 (1990) pp.76-81.

[13] Minami F., Brückner-Foit A., Munz D. and Trolldenier B., "Estimation Procedure for the Weibull Parameter Used in the Local Approach," Int. Jl. Fracture, 54 (1992) pp. 197-210.

[14] Gerald C. F. and Wheatley P. O., "Applied Numerical Analysis," 4th ed., Addison - Wesley Publication, (1989) pp.299-336.

[15] Thoman D. R., Bain L. J. and Antle C. E., "Influences on the Parameters of the Weibull Distribution," Technometrics, 11 (1969) pp.445-460.

[16] Minami F., EL-Shennawy M., Toyoda M., Kajimoto K., Fujii M., Murai R and Yanagisawa E., "Small-Size Fracture Toughness Specimen Using Plastic Constraint by Strength Mis-Matching," Submitted to Mis-Match 96. 